\title{
Botulinum in selected neurological disorders - review
}

\author{
Agata Rocka ${ }^{1, A-D, F} \oplus$, Faustyna Piędel ${ }^{1, A-D \oplus}$, Patryk Piotr Jasielski ${ }^{1, C-E \oplus}$, Mikołaj Piwek ${ }^{1, D-F} \oplus$, \\ Véronique Petit ${ }^{2, A, E-F \oplus}$, Konrad Rejdak ${ }^{2, A, E-F \oplus}$ \\ ${ }^{1}$ Medical University, Lublin, Poland \\ ${ }^{2}$ Department of Neurology, Medical University, Poland \\ A - Research concept and design, B - Collection and/or assembly of data, C - Data analysis and interpretation, \\ $D$ - Writing the article, $E$ - Critical revision of the article, $F$ - Final approval of the article
}

Rocka A, Piędel F, Jasielski PP, Piwek M, Petit V, Rejdak K. Botulinum in selected neurological disorders - review. J Pre-Clin Clin Res. 2021; 15(4): 176-183. doi: $10.26444 / \mathrm{jpccr} / 142880$

\begin{abstract}
Introduction and objective. Botulinum toxin (BoNT) has been used in medicine for many years. BoNT, prevents acetylcholine from being released into synapses, causing flaccid muscles paralysis. The article reviews the current knowledge of botulinum toxin application in the treatment of neurological diseases, focusing on therapeutic efficacy and side-effects. The aim of the review is to analyze the largest possible number of neurological conditions in which the application of botulinum toxin was considered.

Materials and method. A literature review of the last 10 years was conducted using the key words: 'botulinum toxin neurology' in the PubMed database, with the search criteria: clinical trials, free full text in English, research on humans. 2,581 manuscripts were found. After initial analysis, 188 publications were selected for further elaboration. Finally, 61 compatible publications were identified and included in the review.

Abbreviated description of the state of knowledge. In the treatment of Tourette's syndrome with BoNT, despite the reduction in tics frequency, patients did not report any benefits. There are promising reports on the reduction of the intensity of neuropathic pain and neuralgia in trigeminal neuralgia after the use of BoNT-A. Improvement in rest tremor has been seen in patients with Parkinson's disease. Administration of BoNT-A among patients with bruxism was associated with improved sleep quality and reduction of the symptoms intensity. Research confirms the effectiveness of using BoNT in the treatment of bothersome symptoms occurring in migraine, drooling, cervical dystonia and neurogenic bladder.

Conclusions. Although the use of BoNT in neurological diseases is widely studied and used, the appropriate administration technique and safety of use are worth further research.
\end{abstract}

\section{Key words}

botulinum, neurology, cervical dystonia, migraine, overactive bladder

\section{INTRODUCTION}

Since the approval of botulinum toxin (BoNT, BT) by the US Food and Drug Administration (FDA) in 1979 for human research, it started becoming more and more widely used in clinical medicine [1]. BoNT drugs are 'biological drugs' because their main ingredient is the botulinum neurotoxin (BNT) protein; moreover, they contain complexing proteins (CP) and auxiliary substances [2]. Botulinum neurotoxins (BTN) are proteins produced by neurotoxic strains of anaerobic bacteria and bacteria of the genus Clostridium. BTNs prevent the release of acetylcholine at the cholinergic ends of the peripheral nerves of the skeletal and autonomic nervous system, weakening the neuromuscular junction, causing flaccid paralysis $[2,3]$. Of the eight toxin subtypes (A$\mathrm{H})$, only toxins $\mathrm{A}$ and $\mathrm{B}$ are FDA approved for therapeutic use and used in motor disorders. BT drugs used in the treatment are onabotulinumtoxin A (Botox), abobotulinumtoxinA (Dysport), incobotulinumtoxinA (Xeomin) and RimabotulinumtoxinB (Myobloc or NeuroBloc), unavailable in Poland. BT is widely used in neurology with an average duration of BT treatment of three months [4]. The first uses of BT in neurology were eyelid spasms, cervical dystonia

Address for correspondence: Agata Rocka, Medical University, Jaczewskiego 8, 20-954 Lublin, Poland

E-mail: agatarocka2@gmail.com

Received: 16.08.2021; accepted: 05.10.2021; first published: 14.10.2021 and spasticity [1]; however, evidence-based information on optimal dosing for clinical use is limited. The exact amount of BoNT doses, the method and frequency of their administration, depending on the severity of symptoms in a given neurological disease, can improve the quality of life for many people worldwide. This review is an attempt to systematize information on the effectiveness and safety of the botulinum toxin used inthe treatment of common neurological diseases

\section{MATERIALS AND METHOD}

A literature review of the last 10 years was carried out using the key words: 'botulinum toxin neurology' in the PubMed database, and using the search criteria: clinical trials, free full text in english, research on humans. Due to the large amount of literature, the aim of the review was to collect and present the current knowledge on the wide use of botulinum toxin in neurology, paying attention to therapeutic efficacy and side-ffects.

\section{RESULTS}

2,581 manuscripts were found. After initial analysis, 188 publications were selected for further elaboration, and finally, 


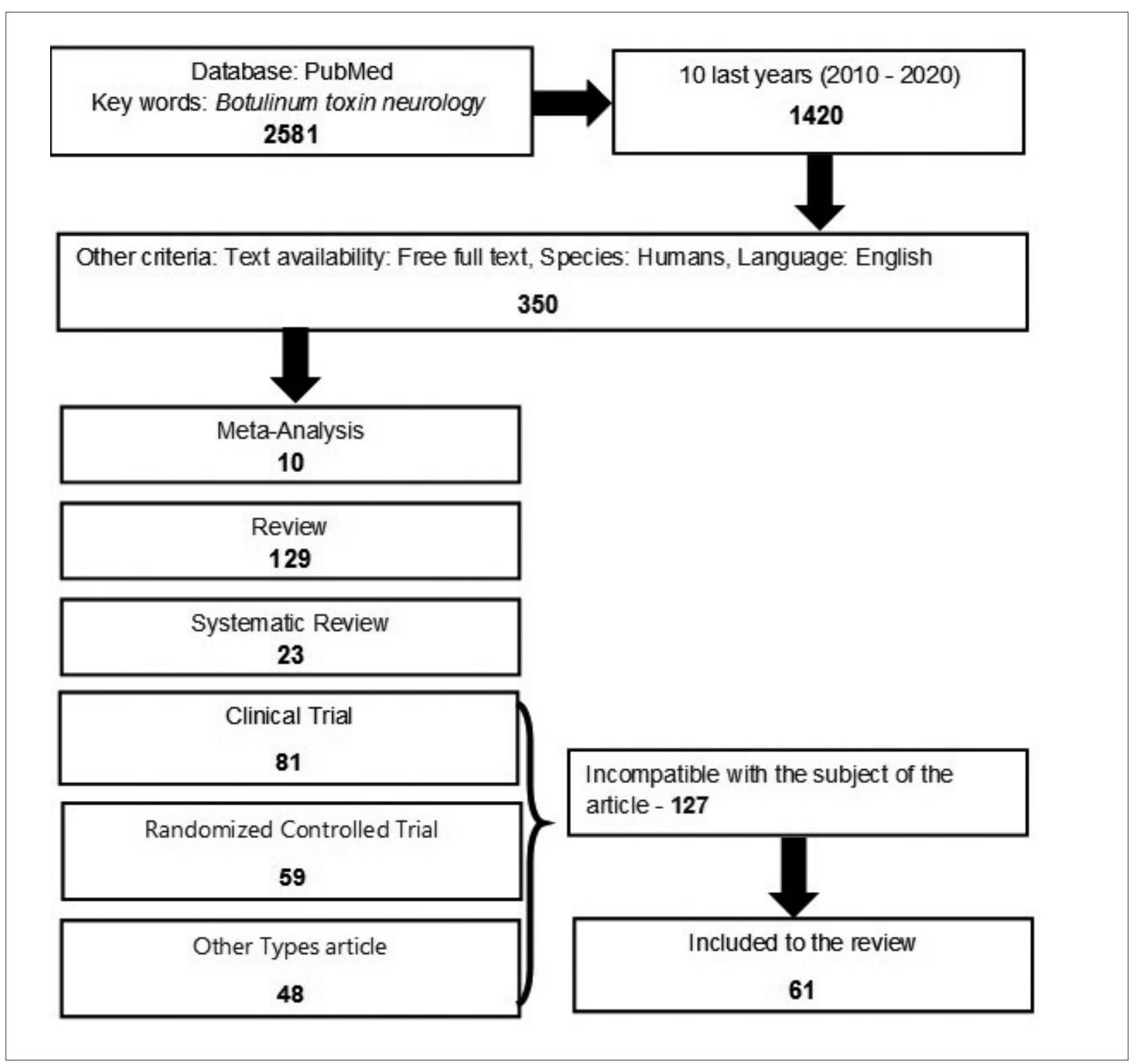

Figure 1. Flow chart of the search for articles for inclusion in the review

61 compatible publications were identified and consulted to compile the review. 127 Manuscripts were rejected due to: poor quality of data, vague patients selection, poor quality of statistical analysis, uncertain results. Results of the search are summarized in Figure 1.

\section{STATE OF KNOWLEDGE}

History of botulinum. BoNT has its origins dating back to 1895 when it was discovered by the Belgian bacteriologist van Ermengem. The bacterium (Clostridium botulinum) produces a protein that may be the strongest neurotoxin known to date. In the 1920s, Sommer isolated BoNT type A (BoNT-A) in a purified form and in 1946, Schantz isolated the toxin in a crystalline form. In 1950, Brooks showed that the toxin blocks the release of acetylcholine in motor neurons, causing the muscles to relax. The earliest clinical applications were described by Scott et al. in 1977, and concerned the possibility of non-surgical treatment of strabismus in primates. The first publication concerning the use of botulinum toxin on humans as a therapeutic agent took place in 1980 [5]. In 2000, the Food and Drug Administration (FDA) approved Botox for the treatment of cervical dystonia in adults to alleviate abnormal head posture and neck pain associated with this condition. In 2004, it was approved for the treatment of severe primary axillary hyperhidrosis which did not respond adequately to topical medications [6]. Over the years, BoNT was increasing used in more and more disease entities, especially in the treatment of migraine and neurodegenerative diseases.

Mechanism of action of botulinum toxin. BT acts on nerve endings by cleaving and inactivating proteins of the SNARE complex, leading to an inhibition of conduction in nerve synapses. All BoNT serotypes share the same structure and function, consisting of a light chain (LC, $\sim 50 \mathrm{kDa}$ ) and a heavy chain (HC, 100 kDa) linked by a disulfide bond. HC 
contains two domains: the C-terminal HC domain mediates binding to receptors and the $\mathrm{N}$-terminal $\mathrm{HN}$ domain mediates the movement of the LC chain across endosomal membranes.

LC acts like a protease on neurons. The BoNT-A, C and E proteins operate at different sites on the SNAP-25 peripheral membrane proteins. The BoNT-B, D, F and G proteins function at different sites on the homologous membrane proteins of the synaptic vesicle VAMP 1, 2 and 3. BoNT-C also cleaves membrane protein syntaxin 1 . Cleavage of any of the three neuronal SNARE proteins blocks the fusion of synaptic vesicles with plasma membranes, thus preventing the release of neurotransmitters from neurons $[7,8,9]$.

\section{Use of ultrasound (ultrasonography) and electromyography} (EMG) in the supply of botulinum toxin. The toxin is administered intramuscularly. Additional application of ultrasound (USG) or electromyography (EMG) allows for precise definition of the injection site [4]. Both USG and ES are effective methods of BoNT-A injection [10]. The use of ultrasound for the BoNT-A supply, compared to the conventional method, enables a more precise administration of the agent, thus giving better clinical results $[11,12]$. The study by M. Porta indicated that the use of ultrasound while administering BoNT to the salivary glands increases the safety of a given method of treating drooling [12].

Use of botulinum toxin in the treatment of selected neurological diseases. BoNT is known to be the most dangerous bioterrorism agent. Despite its harmfulness, it is used in the treatment of an increasing number of diseases, and studies to confirm its effectiveness and safety are constantly ongoing. The review discusses the use of BoNT in combating the symptoms of many neurological diseases: stroke, multiple sclerosis, Parkinson's disease, dystonia, nervous tics, essential tremor, bruxism, over-active bladder, drooling, migraine, neuropathic pain, trismus, mild primary spasm eyelids, and hyperhidrosis. There are also reports on the effectiveness of BoNT in the treatment Huntington's disease and cerebral palsy $[13,14]$.

Stroke. The first randomized trials on the use of Botox in the treatment of upper and lower limb spasticity were carried out in 2000 [15]. The most common cause of spasticity, i.e. the state of increased muscle tension accompanying paresis of the limbs, excessive tendon reflexes and pathological symptoms, such as Babinski's reflex, is stroke [16]. According to Watkins et al., post-stroke spasticity occurs in about $27.3 \%$ cases in the upper limbs, and in about $31.2 \%$ in the lower limbs [17]. BoNT-A injections are a safe method of treatment in spasticity after stroke, reducing the increased muscle tension and improving the range of passive movements of the upper and lower limbs $[18,19]$. Not only spasticity after stroke, but also spasticity after central nervous system injuries and in multiple sclerosis (MS), having a similar pathomechanism, can be treated with BoNT-A [18]. In a study by Gordon et al. for 42 weeks in four treatment cycles, 111 patients who took onabotulinumtoxin A showed a significant improvement in the reduction of muscle tension assessed by the Spasticity Scale: Ashworth Scale - Modified Ashworth Scale (MAS) [20]. In the studies by Baricich et al. on 26 patients, a significant reduction in muscle tone was observed in all cases, 30 and 90 days after treatment [21]. In those two studies, functional improvements were found, as assessed by the Disability Assessment Scale
(DAS) [20, 21]. In another study, after consecutive BoNT-A treatment sessions, an extension of the intervals between successive injections was observed even at a similar dose [22]. In the studies by Picelia et al. presenting data from the register of 24 Italian centres dealing with neurorehabilitation, it was found that the average dose of Botox was $316.7 \pm 79.1$ units for the upper limb, and $327.8 \pm 152.3$ units concerning the lower limb in the treatment of limb spasticity [23].

Multiple sclerosis. Not only post-stroke spasticity, but also spasticity in multiple scerosis (MS) can be treated with BoNT-A [18]. BoNT can alleviate symptoms of urinary incontinence among patients with over-active bladder in MS [24]. Swallowing disorders are a common complication of MS, occurring in $30-40 \%$ of patients. The effectiveness of BoNT-A in swallowing disorders in patients with MS has been studied. After injection of BoNT-A under EMG control into the overactive laryngopharyngeal muscle conducted on 14 patients with MS, swallowing improved [25]. Interesting results were obtained by researchers in a double-blind, randomized trial evaluating the effectiveness and safety of BoNT-A in reducing tremor associated with MS. 23 patients were randomized into BoNT-A and placebo groups, and tremor was assessed after first administration and after six and 12 weeks of treatment using the Bain scale, and evaluation based on writing and drawing the Archimedes spiral. After six and 12 weeks, a statistically significant $(\mathrm{p}=0.0005 ; \mathrm{p}=0.0001)$ reduction of tremor was noted among patients who received BoNT-A, compared to the placebo group [26].

Parkinson's disease. The underlying cause of Parkinson's disease (PD) is the degeneration of structures in the brain. The atrophy of cells belonging to the dopaminergic system causes symptoms such as slowness of movement (bradykinesia), tremor at rest, muscle stiffness, disturbances in gait and posture. Despite treatment and rehabilitation, the disease progresses and patients face many difficulties in everyday life. It is estimated that PD occurs in $0.15-0.3 \%$ of the general population. It is a progressive disease in which the therapeutic process is based on inhibiting its progress [27]. Due to muscle dysfunction, patients often develop dystonia, which often causes pain and restricts the range of motion.

One of the randomized, double-blind studies conducted showed the effectiveness of BoNT-A in patients with toe dystonia. The study included 45 patients with painful and limiting movement, dystonic plantar flexion. BoNT-A in an amount of 100 UI was injected twice, two months apart, into the long flexor muscles and the short flexor muscles. An improvement in the overall clinical impression was observed in the test group, compared to the placebo group $(\mathrm{p}=0.039)$. Moreover, a significant reduction in pain and dystonia after th injection of BoNT was noticed; however, no significant differences were found in relation to the placebo group [28]. Another study was carried out on 12 patients with dystonia of the upper or lower extremities who were treated with BoNT-A at an average dose of 241.66 UI. Significant pain reduction was observed using the NRS Numerical Rating Scale (NRS) within four weeks after injection $(p=0.033)$. As in the previous study, no significant difference was found compared to the placebo group $(\mathrm{p}=0.70)$ [29]. A 3-year randomized, double-blind study (2012-2015) by Mittal et al., which enrolled 30 patients with Parkinson's Disease who received injection of incobotulinumtoxin A (IncoA), showed 
significant improvement in resting tremor and a decrease in tremor severity at four and eight weeks after injection. Moreover, it was noted that muscle weakness was a rare undesirable symptom [30].

Cervical dystonia. Dystonia is a neurological syndrome characterized by sustained and often repeated involuntary movements of the antagonist muscles. The etiology of dystonia may be primary and of unknown cause, or secondary to neurological diseases, medications or tumours [31]. In cervical dystonia (CD), the most common form of primary dystonia, changes mainly affect the neck muscles [32]. The first-line treatment of $\mathrm{CD}$ is the injection of BoNT-A into dystonic muscles [33]. A study by Huang et al. Showed a significant reduction in muscle tension and improvement in the quality of life after using BoNT-A injections under ultrasound guidance [34]. Another analysis showed a greater benefit from physical therapy in patients after previous BoNT-A use [35]. BoNT is used as a first-line treatment for $\mathrm{CD}$, however, because many patients discontinue therapy, new methods of optimizing CD treatment with the use of BoNT-A are being sought $[36,37]$.

It is worth noting that the repeated application of BoNT may cause changes in the muscle fibers, leading to a reduction in muscle strength [38]. BoNT is also used as the first-line drug in the treatment of facial dystonia [39].

Tourette's syndrome. Tourette's syndrome (or Gilles de la Tourette's syndrome) is defined as the presence of tics in the form of involuntary movements, repeating words, often obscene, and blinking eyelids. Although the disease has a family background, the cause of Tourette's syndrome has yet to be understood. Treatment is mainly based on psychotherapy and pharmacological treatment (dopamine antagonists, L-receptor agonists). The side-effects of pharmacological treatment contribute to the further search for new therapeutic methods. Botulinum neurotoxin in the treatment of tics inhibits neuromuscular transmission and weakens hyperactive muscle fibers involved in the production of involuntary movements. In addition to alleviating excessive muscle activity, botulinum neurotoxin appears to reduce sensation and pain associated with tics. Similar mechanisms may underlie the therapeutic effect of BoNT injected into the vocal cords, which reduce phonic tics [40]. However, research into the effects of BoNT is limited because of the serious side-effects due to the ability of botulin to block dopamine. BoNT has proven appropriate, especially in patients with focal and dystonic tics $[41,42]$.

A randomized, double-blind study of BoNT in the treatment of motor tics showed a $39 \%$ reduction in tics per minute using video recording after BoNT administration. However, patients did not report an overall benefit from treatment [43]. Kim et al. Described 21-year-old patient with abnormal motor tics with hyperflexia and hyperextension of the cervical spine for over 10 years. One of the treatments was application of BoNT to the neck muscles along with medications for tic disorders. However, neck movement due to the tics disorder did not improve. Three days after BoNT administration, the weakness of all limbs gradually worsened. Finally, the patient underwent laminoplasty and posterior fixation.

The small number of randomized results available and the observed side-effects make it impossible to define a clearly positive treatment effect. Further research is needed to confirm the safety and effectiveness of the BoNT in the treatment of nervous tics, including Tourette's syndrome [44].

Essential tremor. Essential tremor (ET) is one of the most common symptoms of movement disorder, manifested by trembling, and mainly affects hands, forearms and head. There are three basic types of tremors: resting, postural and kinetic. Epidemiological studies show that the incidence of ET increases with age, with the disease occurring in $40 / 1,000$ subjects after the age of 65 [45]. ET has an adverse effect on daily functioning with patients experiencing problems in performing daily activities. The treatment includes primidone, propranolol and topiramate. The use of botulinum toxin injections is of increasing interest [46]. Botulinum toxin A-haemagglutinin complex injections seems to improve clinical condition by reducing the occurrence of symptoms in the short term (up to 12 weeks) among people with spontaneous hand tremor. On the other hand, administered therapy is often associated with side-effects, of whch a fairly common transient side-effect is a dose-related feeling of weakness. There are no results of long-term therapy in people with idiopathic hand tremor [47].

Bruxism. Bruxism is a pathological friction or grinding of opposite rows of upper and lower molars. It occurs most often at night (Sleep Bruxism - SB) and is classified as a parasomnia. The treatment used so far, such as psychotherapy or sedatives, often does not produce the expected effect. Use of BoNT-A injection gives promising results and a randomized, double-blind study conducted by Ondo et al. show the effectiveness and safety of the BoNT-A in bruxism treatment. Symptomatic patients were administered $200 \mathrm{U}$ BoNT-A (60 U to each masseter muscle and $40 \mathrm{U}$ to each of the temporal muscles), the effects were then assessed four to eight weeks after the first injection. After administration of BoNT-A, improvement in the quality and duration of sleep were observed. Moreover, the overall clinical impression scale measuring the severity of present CGI symptoms $(\mathrm{p}<0.05)$ and visual analogue scale (VAS; $\mathrm{p}<0.05$ ) showed promising results in the test group. However, the authors emphasize that there is a need for multicentre studies to confirm the obtained study results [48].

In another study by Shim YJ., 30 patients were included and divided into equal research and control groups. Control subjects were injected with saline into both masseter muscles, while the masseter muscles of the research group were injected with BoNT-A. The effectiveness of the method was monitored using audio-video-polysomnographic recordings at four and 12 weeks after injection. Among 23 (study group 13) patients who completed the study, it was found that the peak EMG amplitude during SB showed a significant time and group interaction $(\mathrm{p}=0.001)$. However, the injection reduced peak EMG pulse amplitude during SB only in the 12 -week treatment group ( $\mathrm{p}<0.0001)$. A single injection of BoNT-A did not reduce SB symptoms, but affected the intensity of SB [49]. Another study showed a $>10 \%$ decrease in the range of mandibular movements and in the occlusal force $(\mathrm{BF} \%)$ compared to intial value after the administration of BoNT-A $140 \mathrm{U}$ to the masseter muscles and temples. After 15 days, the occlusal force decreased $(\mathrm{p}=0.028)$. Occlusion values also decreased after 15 days $(\mathrm{p}=0.028)$, and after 90 days $(p=0.043)$ [50]. Satisfactory results were described in 
the article in which 24 patients were randomly divided into three groups $(n=8)$. Treated by bilateral intramuscular injections, a placebo group, and a non-infiltration group. The effect of BoNT-A was assessed in the treatment of myofascial pain at rest and during chewing, the power of which was also assessed. Observations were made after one week, three months and six months. Pain at rest decreased among patients treated with BoNT-A. Significant change in the maximum occlusion strength was observed in the BoNT-A group compared to the other groups [51]. Some studies have shown promising results indicating the need for further research in this direction.

Urologic pathologic conditions. Over-active bladder (OAB) is a syndrome consisting of at least one of four symptoms: urge to urinate, urge urinary incontinence, frequent urination and nocturia [52]. In August 2011, BoNT was finally approved by the FDA for the treatment of adult patients with over-active bladder urinary incontinence associated with conditions such as spinal cord injury and MS. The FDA reports that BoNT-A can alleviate the symptoms of urinary incontinence in patients with an over-active bladder associated with a neurological condition for up to 10 months [24]. A randomized study by Amundsen et al. compared two treatments with $200 \mathrm{U}$ IncoA and the methods of sacral nerve neuromodulation (SNM) in treatment-resistant patients - urgency urinary incontinency (UUI). The results indicated that both treatments led to a sustained and similar reduction in mean daily urination over a 24-month period. Patients using BoNT-A showed a greater likelihood of complete recovery from UUI in the first six months, and higher satisfaction and acceptance of treatment within 24 months. It was noted that in the group using BoNT there was an increased risk of urinary tract infections [53]. One of the largest studies conducted by Reitz et al. demonstrated the safety and efficacy of $300 \mathrm{U}$ botulinum toxin injections on 261 patients with abnormal detrusor and urinary bladder sphincter (neurogenic bladder) innervation [54]. The available studies confirm an increase in the efficiency of the bladder with the use of botulinum toxin.

Sialorrhoea. Hypersialosis and drooling are associated with many neurological disorders [55]. The symptoms are especially relevant to patients with cerebral palsy, traumatic encephalopathy, parkinson's disease or amyotrophic lateral sclerosis. It has been shown that the percutaneous injection of BoNT-A into the salivary glands is an effective way of removing excessive drooling associated with neurological disorders [56, 57]. Available research results confirm the effectiveness of BoNT-A injections in drooling reduction $[58,59]$. A double-blind randomized trial conducted by Jost et al. showed reduction in unstimulated salivation after the use of IncoA. 30 patients were included in the study, 19 of whom developed hypersialosis after stroke. A statistically significant difference $(\mathrm{p}=0.004)$ occurred at week four after administration of $100 \mathrm{U}$ IncoA, compared to the placebo group. The most common treatment-related adverse effects were dry mouth and dysphagia [60].

Migraine. Chronic migraine (CM) is defined as a headache occurring $\geq 15$ days a month for $>$ three months, which can be characterized as migraine headache $\geq$ eight days a month [61]. Inadequate CM control contributes to the search for new therapeutic solutions. One of the promising ways to control pain in CM is the use of BoNT-A. The action of BoNT-A is focused mainly on the inflammatory mediators releases inhibition and pain reduction from the trigeminal and peripheral nerve endings, e.g. greater occipital spinal nerve, which leads to central desensitization. BoNT-A is given in cycles every 12 weeks. The effectiveness of therapy should be assessed after at least three cycles of BoNT-A administration [62]. However, due to the small number of research results, BoNT-A has only been registered in the treatment of chronic migraine in some countries, including: USA, Italy and Poland [61-63].

The safety and efficacy of IncoA was assessed in a doubleblind, controlled phase III PREEMPT II trial with two intramuscular injections every 12 weeks over a 24 -week trial period. IncoA administration statistically significantly $(\mathrm{p}<0.001)$ reduced the frequency of headache days within 28 days from the completion of the injection from the baseline value. In addition, also in the later period (up to 21-24 weeks) after treatment, IncoA administration gave better results than in the placebo group. The occurrence of only a few adverse events with good effectiveness supports the use of IncoA in prevention of headaches among people with chronic migraine [64].

The efficacy, tolerability, and safety of IncoA in the treatment of CM were also assessed in 108-week multicentre COMPEL study. There was a significant reduction in the number of headache days over 28 days at all time points $(\mathrm{p}<0.0001)$ [61].

An important clinical aspect of the BoNT-A use in CM is the screening procedure, which includes an interview analysis and physical examination. The qualification for treatment is carried out by a neurologist. Its most important part is confirmation of the diagnosis of chronic migraine [62].

Analgesic effect, neuropathic pain. Peripheral neuropathic pain is a serious condition that affects patients with a variety of medical conditions, but treatment options are limited. A randomized, double-blind, placebo-controlled study was conducted on 152 patients to evaluate the effectiveness of BoNT-A injection in relieving neuropathic pain. After an interval of 12 weeks, BoNT-A was administered twice subcutaneously (up to $300 \mathrm{U}$ ) and placebo was administered in the control group. 24 weeks after the first injection, the mean weekly pain intensity was measured in both groups. Twice administered BoNT-A significantly reduced the intensity of peripheral neuropathic pain compared to placebo $(\mathrm{p}<0.0001)$ [65].

Trigeminal neuralgia is a painful condition that significantly worsens the quality of life and often leads to difficulties in everyday functioning. In a study of the clinical effects and safety of the BoNT-A in neuralgia alleviation conducted on 87 patients with trigeminal neuralgia, satisfactory results were achieved. Patients were assessed one week before and eight weeks after BoNT-A injection. After treatment, in addition to clinically significant pain relief, better social and mental functioning and better sleep quality were also achieved ( $\mathrm{p}<0.01)$. However, physical fitness did not improve significantly $(\mathrm{p}=0.371$ ) [66]. Another study showed significant pain reduction 12 weeks after BoNT-A administration $(\mathrm{p}<0.0001)$. This suggests that BoNT-A may be a potentially effective therapeutic method in severe cases of trigeminal neuralgia [67]. The presence of hallux valgus is associated with pain and thus reduced efficiency. 
A randomized, double-blind, controlled trial evaluated the effect of intramuscular administration of BoNT-A among 16 patients with hallux valgus. The assessments were made one, two, three and six months after the intramuscular injection of the foot. There was a greater improvement in pain scores in the BoNT-A group than in the saline injection group ( $p$ $<0.001$ ). The results of the study showed that BoNT-A could be a potential aid in pain relief associated with hallux valgus over a six-month period [68].

Neuropathic pain significantly worsens the quality of life of people with spinal cord injury. The assessment of the effectiveness of BoNT-A in neuropathic pain reduction among 40 patients after spinal cord injury was undertaken by Han et al. Researchers performed a single $200 \mathrm{U}$ injection under the skin, and then used the Visual Analog Scale (VAS) to assess the pain level of patients after four and eight weeks, respectively. After two months, $45 \%$ of BoNT-A recipients reported a pain reduction of around $20 \%$ from baseline, compared to $10 \%$ in the placebo group.

It is worth noting that pain relief among patients after BoNT-A injection was not associated with deterioration of sensory and motor functions below the level of spinal cord injury. BoNT-A may constitute a new, promising therapeutic path for patients with neuropathic pain and could potentially improve their daily functioning [69].

Trismus. Trismus from the Greek word means 'grinding', refers to limitation of the range of motion of the jaws. Trismus usually originates from permanent tetanic contraction of the masticatory muscles. Trismus refers to the limited opening of the mouth regardless of etiology [70].

Temporomandibular disease (TMD). Characterized by pain and disturbances in the joints and / or muscles with associated structures. The symptoms include mainly: headaches, pain in the face and neck, and limited opening of the mouth [71]. The effectiveness of TMD treatment with botulinum toxin or laser therapy is due to its muscle relaxant effect, reducing pain and improving the balance of mandibular functions. A randomized trial compared the use of lowlevel laser therapy with a power of $100 \mathrm{~mW}$ (wavelength: $830 \mathrm{~nm}$ ) to the effectiveness of botulinum toxin. Patients received $30 \mathrm{U}$ of BoNT-A in the first session and $15 \mathrm{U}$ after 15 days. The effectiveness of both methods was assessed by measuring pain using a visual analog scale (VAS), and measuring opening of the mouth with a digital caliper. The treatments were effective in pain reduction; however, the effect of the laser therapy was achieved faster than by the use of BoNT-A. Both treatments showed no statistically significant improvement in mouth opening [72]

In another study, BoNT-B was injected into the masseter muscles of patients with spastic trismus. The procedure was used on 11 patients with trismus caused by diseases (stroke, hypoxic-ischemic encephalopathy or traumatic injury). Mouth opening, salivation, and overall achievement of the clinical goal were assessed. Three weeks after BoNT-B injection, significantly larger mouth opening was observed compared to placebo treatment $(\mathrm{P}<0.05)$. Apart from the muscle paralyzing effect, the goal achievement scale showed a clinical benefit for the BoNT-B group $(\mathrm{p}<0.01)$ [73].

The above studies show the effectiveness of BoNT in the treatment of pain and in increasing mouth opening among patients with trismus.
Blepharospasm. Benign primary blepharospasm (BEB) is a focal facial dystonia characterized by excessive blinking and involuntary contraction of the eyelids, affecting approximately 30/100,000 people. So far, no long-term, effective method of treatment has been discovered. In most cases, blepharospasm is an idiopathic disorder that usually lasts a lifetime. The injection of BoNT-A is the cornerstone in the management of patients with BEB due to its proven safety and efficacy $[74,75,76]$. Repeated administration of BoNT is usually required every three or four months. It is worth noting that the subsequent injections are not always as effective as the first [77].

In a study by Lee et al., The effectiveness of BoNT-A injections were assessed over a period of five years in 268 patients diagnosed with spontaneous blepharospasm. Treatment efficacy and dose of repeated injections were assessed at $0.1 \pm 0.5 \mathrm{U}$ and $39.1 \pm 4.0 \mathrm{U}$, respectively, with no significant differences for repeated injections. The duration of response was $5.9 \pm 5.4$ months, but decreased significantly with consecutive injections ( $\mathrm{p}<0.01)$. However, it is worth noting that in the above study, the use of various preparations of botulinum toxin was taken into account, which could adversely affect the results [78].

Hyperhidrosis. Excessive sweating is a condition associated with significant costs and social discomfort of the people it affects. Topical treatment options are limited. The use of BoNT-A has been approved by the FDA for focal axillary hyperhidrosis that is unresponsive to topical treatment. [79]. The mechanism of action is based on blocking neuroglandular conduction by inhibiting acetylcholine release from cholinergic neurons that innervate sweat glands [80].

One of the studies confirming the effectiveness of BoNT-A in hyperhidrosis is a 52-week multicentre, randomized trial involving 332 patients. A significantly higher response rate was observed in the BoNT-A group than in the placebo group ( $\mathrm{p}<0.001$ ). Use of BoNT was well tolerated. There were no significant differences in the frequency of adverse effects between the BoNT group and the placebo group. After injection, the effectiveness of BoNT has been reported up to six or seven months [81].

The social discomfort associated with hyperhidrosis makes it very important to assess patient satisfaction with the treatment. In a multicentre randomized study of the effectiveness of BoNT-A in bilateral axillary hyperhidrosis, significantly greater satisfaction was observed after four weeks in the group receiving BoNT than in the placebo group $(\mathrm{p}<0.001)$ [82].

\section{CONCLUSIONS}

BoNT-A treatment is usually based on placing a perineural block and relieving the symptoms of the disease. Use of BoNT-A injections reduces symptoms among patients with many neurological diseases. BoNT-A injections, reducing increased muscle tension and improving the range of passive limb movements, are used not only in spasticity after stroke, but also after injuries of the central nervous system and in MS. BoNT-A can also be used in Parkinson's disease. The first-line treatment of CD is the injection of BoNT-A into the dystonic muscles. BoNT-A can also be used to improve the quality of life among patients with nervous 
tics, ET, bruxism, hypersialosis and drooling. Numerous studies confirm the effectiveness of botulinum toxin in the treatment of neurogenic bladder. In some countries, a new treatment for migraine employs BoNT-A. BoNT-A may represent a promising therapeutic pathway for patients to relieve neuropathic pain and improve their daily functioning. Injections under ultrasound and possibly during EMG contributes to increased safety and effectiveness of BoNT-A.

Although BoNT-A is successfully used in the treatment and support of the treatment of certain neurological diseases, it is also used in various fields of medicine, including ophthalmology, plastic surgery, and especially aesthetic medicine. There is a need for further multi-centre studies to confirm the effectiveness of BoNT-A. Further research could potentially make it possible to specify the injection site and dose of botulinum toxin in a specific disease, as well as improve the method, minimize side-effects and extend the time without symptoms.

\section{REFERENCES}

1. Jabbari B. Botulinum Toxin Treatment in Neurology. Semin Neurol. 2016; 36(1): 3-4. https://doi.org/10.1055/s-0036-1571849

2. Dressler D. Therapeutically relevant features of botulinum toxin drugs. Toxicon. 2020; 175: 64-68. https://doi.org/10.1016/j.toxicon.2019.12.005 3. Pirazzini M, Rossetto O, Eleopra R, et al. Botulinum Neurotoxins: Biology, Pharmacology, and Toxicology. Pharmacol Rev. 2017; 69(2): 200-235. https://dx.doi.org/10.1124\%2Fpr.116.012658

4. Tater P, Pandey S. Botulinum toxin in movement disorders. Neurol India. 2018; 66: 79-89. https://doi.org/10.4103/0028-3886.226441.

5. Carruthers A. History of the clinical use of botulinum toxin A and B. Clin Dermatol. 2003; 21: 469-472. https://doi.org/10.1016/j. clindermatol.2003.11.003

6.López del Val LJ, Castro García A. Toxina Botulínica: Aplicaciones Terapéuticas. 2nd ed. Barcelona, Spain: Masson; 2002. p. 3-21.

7.Zhang S, Masuyer G, Zhang J, et al. Identification and characterization of a novel botulinum neurotoxin. Nat Commun. 2017; 8: 14130. https:// doi.org/10.1038/ncomms14130.

8. Jahn R, Scheller R.H. SNAREs-engines for membrane fusion. Nat Rev Mol Cell Biol. 2006; 7: 631-643. https://doi.org/10.1038/nrm2002

9. Sudhof TC, Rothman JE. Membrane fusion: grappling with SNARE and SM proteins. Science. 2009; 323: 474-477. https://doi.org/10.1126/ science. 1161748

10. Turna IF, Erhan B, Gunduz NB, et al. The effects of different injection techniques of botulinum toxin in post-stroke patients with plantar flexor spasticity. Acta Neurol Belg. 2020; 120(3): 639-643. https://doi. org/10.1007/s13760-018-0969-x

11. Santamato A, Micello MF, Panza F, et al. Can botulinum toxin type A injection technique influence the clinical outcome of patients with poststroke upper limb spasticity? A randomized controlled trial comparing manual needle placement and ultrasound-guided injection techniques. J Neurol Sci. 2014; 347(1-2): 39-43. https://doi.org/10.1016/j.jns.2014.09.016

12. Porta M, Gamba M, Bertacchi G, et al. Treatment of sialorrhoea with ultrasound guided botulinum toxin type injection in patients with neurological disorders. J Neurol Neurosurg Psychiatry. 2001; 70: 538540. https://dx.doi.org/10.1136\%2Fjnnp.70.4.538

13. Tilton A, Russman B, Aydin R, et al. Abobotulinumtoxin A (Dysport ${ }^{\circledR}$ ) Improves Function According to Goal Attainment in Children With Dynamic Equinus Due to Cerebral Palsy. J Child Neurol. 2017; 32(5): 482-487. https://doi.org/10.1177/0883073816686910

14. Bachoud-Lévi AC, Ferreira J, Massart R, et al. International Guidelines for the Treatment of Huntington's Disease. Front Neurol. 2019; 3: 10: 710. https://doi.org/10.3389/fneur.2019.00710

15. Richardson D, Sheean G, Werring D, et al. Evaluating the role of botulinum toxin in the management of focal hypertonia in adults. J Neurol Neurosurg Psychiatry 2000; 69: 499-506. https://doi.org/10.1136/ jnnp.69.4.499

16. Sławek J, Bogucki A, Budrewicz S, et al. Leczenie toksyną botulinową spastyczności kończyny dolnej po udarze mózgu — rekomendacje Sekcji Schorzeń Pozapiramidowych Polskiego Towarzystwa Neurologicznego, Polskiego Towarzystwa Choroby Parkinsona i Innych Zaburzeń Ruchowych oraz Interdyscyplinarnej Grupy Ekspertów. Pol Przegl Neurol. 2016; 12(2): 65-79. https://journals.viamedica.pl/polski_ przeglad_neurologiczny/article/view/48569/37744
17. Watkins CL, Leathley MJ, Gregson JM, et al. Prevalence of spasticity post stroke. Clin Rehabil. 2002; 16: 515-522. https://doi. org/10.1191/0269215502cr512oa

18. Sławek J, Koziorowski D, Dec-Ćwiek M, et al. Rekomendacje interdyscyplinarnej grupy ekspertów w zakresie kompleksowego i długofalowego leczenia spastyczności toksyną botulinową typu A. Pol Przegl Neurol. 2018; 14(2): 47-59. https://journals.viamedica.pl/ polski_przeglad_neurologiczny/article/view/58409

19. Sławek J. Toksyna botulinowa w leczeniu spastyczności kończyny górnej. Pol Przegl Neurol. 2015; 11(4): 190-201. https://journals.viamedica.pl/ polski_przeglad_neurologiczny/article/view/44548/34738

20. Gordon MF, Brashear A, Elovic E, et al. BOTOX Poststroke Spasticity Study Group. Repeated dosing of botulinum toxin type A for upper limb spasticity following stroke. Neurology. 2004; 63(10): 1971-1973. https://doi.org/10.1212/01.wnl.0000144349.95487.91

21. Lagalla G, Danni M, Reiter F, et al. Post-stroke spasticity management with repeated botulinum toxin injections in the upper limb. Am J Phys Med Rehab. 2000; 79(4): 377-384. https://doi.org/10.1097/00002060200007000-00010

22. Baricich A, Grana E, Carda S, et al. High doses of onabotulinumtoxinA in post-stroke spasticity: a retrospective analysis. J Neural Transm (Vienna). 2015; 122(9): 1283-1287. https://doi.org/10.1007/s00702-0151384-6

23. Picelli A, Baricich A, Cisari C, et al. The Italian real-life post-stroke spasticity survey: unmet needs in the management of spasticity with botulinum toxin type A. Funct Neurol. 2017; 32(2): 89-96. https://doi. org/10.11138/fneur/2017.32.2.089

24. BOTOX (onabotulinumtoxinA) for injection, for intramuscular, intradetrusor, or intradermal use Initial U.S. Approval: 1989. https:// www.accessdata.fda.gov/drugsatfda_docs/label/2017/103000s5302lbl. pdf

25. Van Der Walt A, Sung S, Spelman T, et al. A double-blind, randomized, controlled study of botulinum toxin type A in MSrelated tremor. Neurology. 2012; 79(1): 92-99. https://doi.org/10.1212/ wnl.0b013e31825dcdd9

26. Restivo DA, Marchese-Ragona R, Patti F, et al. Botulinum toxin improves dysphagia associated with multiple sclerosis. Eur J Neurol. 2011; 18(3): 486-490. https://doi.org/10.1111/j.1468-1331.2010.03189.x

27. Capriotti T, Terzakis K. Parkinson Disease. Home Healthc Now. 2016; 34(6): 300-307. https://doi.org/10.1097/nhh.0000000000000398

28. Rieu I, Degos B, Castelnovo G, et al. Incobotulinum toxin A in Parkinson's disease with foot dystonia: A double blind randomized trial. Parkinsonism Relat Disord. 2018; 46: 9-15. https://doi.org/10.1016/j. parkreldis.2017.10.009

29. Bruno V, Freitas ME, Mancini D. Botulinum Toxin Type A for Pain in Advanced Parkinson's Disease. Can J Neurol Sci. 2018; 45(1): 23-29. https://doi.org/10.1017/cjn.2017.245

30. Mittal S, Machado D, Richardson D, et al. Botulinum Toxin in Parkinson Disease Tremor: A Randomized, Double-Blind, Placebo-Controlled Study With a Customized Injection Approach. Mayo Clin Proc. 2017; 92(9): 1359-1367. https://doi.org/10.1016/j.mayocp.2017.06.010

31. Jinnah HA, Factor SA. Diagnosis and treatment of dystonia. Neurol Clin. 2015; 33: 77-100. https://doi.org/10.1016/j.ncl.2014.09.002

32. Snaith A, Wade D. Dystonia. BMJ Clin Evid. 2014; 2014: 1211. https:// www.ncbi.nlm.nih.gov/pmc/articles/PMC3938056/

33. Pirazzini M, Rossetto O, Eleopra R, et al. Botulinum Neurotoksyny: biologia, farmakologia i toksykologia. Pharmacol Rev. 2017; 69: 200-235. https://doi.org/10.1124/pr.116.012658

34. Huang L, Chen HX, Ding XD, et al. Efficacy analysis of ultrasoundguided local injection of botulinum toxin type A treatment with orthopedic joint brace in patients with cervical dystonia. Eur Rev Med Pharmacol Sci. 2015; 19(11): 1989-1993. https://pubmed.ncbi. nlm.nih.gov/26125259/

35. Hu W, Rundle-Gonzalez V, Kulkarni SJ, et al. A randomized study of botulinum toxin versus botulinum toxin plus physical therapy for treatment of cervical dystonia. Parkinsonism Relat Disord. 2019; 63: 195-198. https://doi.org/10.1016/j.parkreldis.2019.02.035

36. Samotus O, Lee J, Jog M. Personalized botulinum toxin type A therapy for cervical dystonia based on kinematic guidance. J Neurol. 2018; 265(6): 1269-1278. https://doi.org/10.1007/s00415-018-8819-6

37. Jinnah HA, Comella CL, Perlmutter J, et al. Dystonia Coalition Investigators. Longitudinal studies of botulinum toxin in cervical dystonia: Why do patients discontinue therapy?. Toxicon. 2018; 147: 89-95. https://doi.org/10.1016/j.toxicon.2017.09.004

38. Ansved T, Odergren T, Borg K. Muscle fiber atrophy in leg muscles after botulinum toxin type A treatment of cervical dystonia. Neurology. 1997; 48: 1440-1442. https://doi.org/10.1212/WNL.48.5.1440

39. Núñez Medrano JA, Fernández E, Georgescu D, et al. Consensus of the Iberoamerican Oculoplastic Society for diagnosis and management of facial dystonia. Arch Soc Esp Oftalmol. 2019; 94(9): 436-440. https:// doi.org/10.1016/j.oftal.2019.03.018 
40. Thenganatt MA, Jankovica J. Recent Advances in Understanding and Managing Tourette Syndrome; Version 1. F1000Res. 2016; 5: F1000 Faculty Rev-152. https://dx.doi.org/10.12688\%2Ff1000research.7424.1

41. Pandey S, Srivanitchapoom P, Kirubakaran R, et al. Botulinum toxin for motor and phonic tics in Tourette's syndrome; Cochrane Database Sys Rev. 2018; 1(1): CD012285. https://doi.org/10.1002/14651858.cd012285. pub2

42. Roth J. The colorful spectrum of Tourette syndrome and its medical, surgical and behavioral therapies; Parkinsonism Relat Disord. 2018; 46 Suppl 1: 75-79. https://doi.org/10.1016/j.parkreldis.2017.08.004

43. Marras C, Andrews D, Sime E, et al. Botulinum toxin for simple motor tics: a randomized, double-blind, controlled clinical trial. Neurology. 2001; 56(5): 605-610. https://doi.org/10.1212/wnl.56.5.605

44. Kim J, Kim JY, Lee JM, et al. Progressive Cervical Spondylotic Myelopathy Caused by Tic Disorders in a Young Adult with Tourette Syndrome. Korean J Neurotrauma. 2019; 15(2): 199-203. https://doi. org/10.13004/kjnt.2019.15.e24

45. Louis ED, Marder K, Cote L, et al. Differences in the prevalence of essential tremor among elderly African, American, whites and Hispanics in Northern Manhattan, NY. Arch Neurol. 1995; 52: 1201-1205. https:// doi.org/10.1001/archneur.1995.00540360079019

46.Zesiewicz TA, Kuo SH. Essential tremor. BMJ Clin Evid. 2015; 15: 1206. https://www.ncbi.nlm.nih.gov/pmc/articles/PMC4681313/

47. Brin MF, Lyons KE, Doucette J, et al. A randomized, double masked, controlled trial of botulinum toxin type $\mathrm{A}$ in essential hand tremor. Neurology. 2001; 56: 1523-1528. https://doi.org/10.1212/wnl.56.11.1523

48. Ondo WG, Simmons JH, Shahid MH, et al. Onabotulinum toxin-A injections for sleep bruxism: A double-blind, placebo-controlled study. Neurology. 2018; 90(7): 559-564. https://doi.org/10.1212/ wnl.0000000000004951

49. Shim YJ, Lee HJ, Park KJ, et al. Botulinum Toxin Therapy for Managing Sleep Bruxism: A Randomized and Placebo-Controlled Trial. Toxins (Basel). 2020; 12(3): 168. https://doi.org/10.3390/toxins12030168

50. Pardo NB, Kerstein RB, Júnior MC, et al. Botulinum toxin type A for controlling bruxism assessed with computerized occlusal analysis: A pilot study. Cranio. 2020; 2: 1-10. https://doi.org/10.1080/08869634.2 020.1724458

51. Jadhao VA, Lokhande N, Habbu SG, et al. Efficacy of botulinum toxin in treating myofascial pain and occlusal force characteristics of masticatory muscles in bruxism. Indian J Dent Res. 2017; 28: 493-497. https://doi.org/10.4103/ijdr.ijdr_125_17

52. Simpson D. Clinical trials of botulinum toxin in the treatment of spasticity. Muscle Nerve Suppl. 1997; 6: 169-175. https://doi.org/10.1002/ (SICI)1097-4598(1997)6+<169::AID-MUS11>3.0.CO;2-1

53. Amundsen CL, Komesu YM, Chermansky C, et al. Pelvic Floor Disorders Network. Two-Year Outcomes of Sacral Neuromodulation Versus Onabotulinumtoxin A for Refractory Urgency Urinary Incontinence: A Randomized Trial. Eur Urol. 2018; 74(1): 66-73. https://doi.org/10.1016/j. eururo.2018.02.011

54. Reitz A, Stöhrer M, Kramer G, et al. European experience of 200 cases treated with botulinum-A toxin injections into the detrusor muscle for urinary incontinence due to neurogenic detrusor overactivity. Eur Urol. 2004; 45(4): 510-515. https://doi.org/10.1016/j.eururo.2003.12.004

55. Banerjee KJ, Glasson C, O'Flaherty SJ. Parotid and submandibular botulinum toxin injections for sialorrhoea in children with cerebra palsy. Dev Med Child Neurol. 2006; 48: 883-887. https://doi.org/10.1017/ s0012162206001939

56. Lovato A, Restivo DA, Ottaviano G, et al. Botulinum toxin therapy: Functional silencing of salivary disorders. Acta Otorhinolaryngol Ital. 2017; 37: 168-171. https://dx.doi.org/10.14639\%2F0392-100X-1608

57. McGeachan AJ, Mcdermott CJ. Management of oral secretions in neurological disease. Pract Neurol. 2017; 17: 96-103. https://doi. org/10.1136/practneurol-2016-001515

58. Mazlan M, Rajasegaran S, Engkasan JP, et al. A Double-Blind Randomized Controlled Trial Investigating the Most Efficacious Dose of Botulinum Toxin-A for Sialorrhea Treatment in Asian Adults with Neurological Diseases. Toxins (Basel). 2015; 7(9): 3758-3770. https:// doi.org/10.3390/toxins7093758

59. Bekkers S, Delsing CP, Kok SE, et al. Randomized controlled trial comparing botulinum vs surgery for drooling in neurodisabilities. Neurology. 2019; 92(11): 1195-1204. https://doi.org/10.1212/ WNL.0000000000007081

60. Jost WH, Friedman A, Michel O, et al. SIAXI: Placebo-controlled, randomized, double-blind study of incobotulinumtoxinA for sialorrhea. Neurology. 2019; 92(17): 1982-1991. https://doi.org/10.1212/ wnl.0000000000007368

61. Winner PK, Blumenfeld AM, Eross EJ, et al. Long-Term Safety and Tolerability of OnabotulinumtoxinA Treatment in Patients with Chronic Migraine: Results of the COMPEL Study. Drug Saf. 2019; 42(8): 1013-1024. https://doi.org/10.1007/s40264-019-00824-3
62. Boczarska-Jedynak M, Sławek J. Praktyczne aspekty leczenia migreny przewlekłej toksyną botulinową typu A. Pol Przegl Neurol. 2017; 13(4): 189-198. https://journals.viamedica.pl/polski_przeglad_neurologiczny/ article/view/55244

63. Liberini P, Pari E, Gazzina S, et al. Technique of injection of onabotulinumtoxin A for chronic migraine: the PREEMPT injection paradigm. Neurol Sci. 2014; 35 Suppl 1: 41-43. https://doi.org/10.1007/ s10072-014-1740-6

64. Diener HC, Dodick DW, Aurora SK, et al. OnabotulinumtoxinA for treatment of chronic migraine: results from the double-blind, randomized, placebo-controlled phase of the PREEMPT 2 trial. Cephalalgia. 2010; 30(7): 804-814. https://doi.org/10.1177/0333102410364677

65. Attal N, de Andrade DC, Adam F, et al. Safety and efficacy of repeated injections of botulinum toxin $\mathrm{A}$ in peripheral neuropathic pain (BOTNEP): a randomised, double-blind, placebo-controlled trial. Lancet Neurol. 2016; 15(6): 555-565. https://doi.org/10.1016/s14744422(16)00017-x

66. Xia JH, He $\mathrm{CH}$, Zhang HF, et al. Botulinum toxin $\mathrm{A}$ in the treatment of trigeminal neuralgia. Int J Neurosci. 2016; 126(4): 348-353. https:// doi.org/10.3109/00207454.2015.1019624

67. Shehata HS, El-Tamawy MS, Shalaby NM, et al. Botulinum toxin-type A: could it be an effective treatment option in intractable trigeminal neuralgia? J Headache Pain. 2013; 14(1): 92. https://doi.org/10.1186/11292377-14-92

68. Wu KP, Chen CK, Lin SC, et al. Botulinum Toxin type A injections for patients with painful hallux valgus: a double-blind, randomized controlled study. Clin Neurol Neurosurg. 2015; 129 Suppl 1: 58-62. https://doi.org/10.1016/s0303-8467(15)30014-7

69. Han ZA, Song DH, Oh HM, et al. Botulinum toxin type A for neuropathic pain in patients with spinal cord injury. Ann Neurol. 2016; 79(4): 569-578. https://doi.org/10.1002/ana.24605

70. Santiago-Rosado LM, Lewison CS. Trismus. In: StatPearls. Treasure Island (FL): StatPearls Publishing; 2020. https://pubmed.ncbi.nlm. nih.gov/29630255/

71. Chang WD, Lee CL, Lin HY, et al. A Meta-analysis of Clinical Effects of Low-level Laser Therapy on Temporomandibular Joint Pain. J Phys Ther Sci. 2014; 26(8): 1297-1300. https://dx.doi.org/10.1589\%2Fjpts.26.1297.

72. De Carli BM, Magro AK, Souza-Silva BN, et al. The effect of laser and botulinum toxin in the treatment of myofascial pain and mouth opening: A randomized clinical trial. J Photochem Photobiol B. 2016; 159: 120-123. https://doi.org/10.1016/j.jphotobiol.2016.03.038

73. Fietzek UM, Kossmehl P, Barthels A, et al. Botulinum toxin B increases mouth opening in patients with spastic trismus. Eur J Neurol. 2009; 16(12): 1299-1304. https://doi.org/10.1111/j.1468-1331.2009.02723.x

74. Bradley EA, Hodge DO, Bartley GB. Benign essential blepharospasm among residents of Olmsted County, Minnesota, 1976 to 1995: an epidemiologic study. Ophthal Plast Reconstr Surg. 2003; 19: 177-181. https://doi.org/10.1097/01.iop.0000065203.88182.cf

75. Hamill EB, Yen MT. The History of Blepharospasm in Medicine. Int Ophthalmol Clin. 2018; 58(1): 3-10. https://doi.org/10.1097/ iio.0000000000000201

76. Simpson DM, Hallett M, Ashman EJ, et al. Practice guideline update summary: Botulinum neurotoxin for the treatment of blepharospasm, cervical dystonia, adult spasticity, and headache: Report of the Guideline Development Subcommittee of the American Academy of Neurology. Neurology. 2016; 86(19): 1818-1826. https://doi.org/10.1212/ wnl.0000000000002560

77. Yen MT. Developments in the treatment of benign essential blepharospasm. Curr Opin Ophthalmol. 2018; 29(5): 440-444. https:// doi.org/10.1097/icu.0000000000000500

78. Lee S, Park S, Lew H. Long-term Efficacy of Botulinum Neurotoxin-A Treatment for Essential Blepharospasm. Korean J Ophthalmol. 2018; 32(1): 1-7. https://dx.doi.org/10.3341\%2Fkjo.2017.0030

79. Flanagan $\mathrm{KH}$, King R, Glaser DA. Botulinum toxin type a versus topical $20 \%$ aluminum chloride for the treatment of moderate to severe primary focal axillary hyperhidrosis. J Drugs Dermatol. 2008; 7(3): 221-227. PMID: 18380203.

80. Hambleton P. Clostridium botulinum toxins: a general review of involvement in disease, structure, mode of action and preparation for clinical use. J Neurol. 1992; 239(1): 16-20. https://doi.org/10.1007/ BF00839205

81. Lowe NJ, Glaser DA, Eadie N, et al. North American Botox in Primary Axillary Hyperhidrosis Clinical Study Group. Botulinum toxin type $A$ in the treatment of primary axillary hyperhidrosis: a 52-week multicenter double-blind, randomized, placebo-controlled study of efficacy and safety. J Am Acad Dermatol. 2007; 56(4): 604-611. https:// doi.org/10.1016/j.jaad.2007.01.009

82. Naumann M, Lowe NJ. Botulinum toxin type A in treatment of bilateral primary axillary hyperhidrosis: randomised, parallel group, double blind, placebo controlled trial. BMJ. 2001; 323: 596-599. https://doi. org/10.1136/bmj.323.7313.596 